\title{
The Effect of Attitude on L2 Learners' Choice of Compensation \& Meta-cognitive Strategies
}

\author{
Abbas Ali Zarei (Corresponding Author) \\ Assistant professor, Imam Khomeini International University, Qazvin, Iran \\ E-mail: aazarei@ikiu.ac.ir, aazarei@yahoo.com \\ Atefeh Elekaei \\ M.A. Islamic Azad University, Takestan, Iran \\ Telephone: +98912-2818077 E-mail: atefehelekaei@yahoo.com
}

Received: 17-09- 2012

Accepted: 19-10- 2012

Published: 01-01- 2013

doi:10.7575/ijalel.v.2n.1p.186

URL: http://dx.doi.org/10.7575/ijalel.v.2n.1p.186

\begin{abstract}
The present study investigates the effect of attitude on the choice of compensation and meta-cognitive strategies of Iranian EFL university students majoring in Teaching English and English Translation. 108 intermediate students from Qazvin and Takestan State and Islamic Azad Universities participated in this study. Data were gathered by means of questionnaires and were analyzed using ANOVA procedures. Results indicated that the level of attitude had a statistically significant effect on the choice of students' compensation strategies $(F=19.407, p<.01)$; however the effect of attitude on the choice of students' meta-cognitive strategies was not significant $(F=.772, p>.05)$.
\end{abstract}

Keywords: attitude - compensation strategies - meta-cognitive strategies

\section{Introduction}

There is little doubt that language learning strategies influence second language learning. The investigation of which strategies learners use, when and how, helps teachers and researchers to find out the development learners have regarding using their abilities, skills, aptitude and proficiencies. At the same time, a wide variety of factors may affect the choice of language learning strategies. Among such factors age, prior knowledge, attitude, motivation, cooperative learning, aptitude, amount of exposure, and anxiety in second language learning have been shown to be strongly related to the choice of language learning strategies (Ames \& Archer, 1988; Guilloteax \& Dornyei, 2008; Ortega, 2003; Vandergrift, 2005). The present study will focus on attitude. In addition, for manageability reasons, this study confines itself to compensation and meta-cognitive strategies.

1.1 Statement of the problem and purpose of the study

Although many researchers have investigated strategies, motivation, autonomy, attitudes, proficiency, cooperative learning and gender (Ames \& Archer, 1988; Guilloteax \& Dornyei, 2008; Ortega, 2003; Vandergrift, 2005), few have done research on variables affecting the choice of learning strategies; therefore, this study will focus on attitude affecting compensation and meta-cognitive strategies.

\subsection{Research questions}

The present study aims to find answers to the following questions: (1) Does attitude level significantly influence the choice of compensation strategies? (2) Does attitude level significantly influence the choice of meta-cognitive strategies?

\section{Literature Review}

\subsection{Language Learning Strategies}

Researchers would like to find out which strategies learners use in their learning, how and when they use them, as well as what makes them assign specific strategies to themselves. Chamot (2004) defines learning strategies as "the conscious thoughts and actions that learners take in order to achieve a learning goal"(p. 14). She holds that:

"Strategic learners have meta-cognitive knowledge about their own thinking and

learning approaches, a good understanding of what a task entails, and the ability

to orchestrate the strategies that best meet both the task demands and their own

learning strengths" (p. 14).

Learners are different, so they choose different strategies based on their understanding of which strategies can possibly contribute to their learning (Cotterall, 2000). In addition, Oxford (1992) believes that in order to teach successfully, 
teachers must be aware of variables such as language learning styles and strategies and many other factors which differ in various learners. Ehrman, Leaver and Oxford (2003, p. 315) claim that three factors are important to make strategies useful: " (a) the strategy relates well to the L2 task at hand, (b) the strategy fits the particular student's learning style preferences to one degree or another, and (c) the student employs the strategy effectively and links it with other relevant strategies".

According to Oxford and Crookall (1989), language learning strategies include Cognitive strategies, Memory strategies, Compensation strategies, Communication strategies, Meta-cognitive strategies, Affective strategies and Social strategies. Cognitive strategies refer to skills which directly manipulate or transform the language. Memory strategies are techniques to store and retrieve new information, respectively. Compensation strategies are behaviors to compensate for missing knowledge. Defining Communication strategies, Oxford and Crookall (1989) maintain that although they are used in listening, reading and writing, they are typically those compensation strategies used in speaking. Metacognitive strategies are behaviors to center, arrange, plan and evaluate one's learning. Affective strategies refer to techniques to gain better control over emotions, attitudes and motivations related to language learning. They also hold that Social strategies are actions which involve other people in language learning.

A number of studies have been conducted on learning strategies and variables affecting them (Oxford \& Ehrman, 1995; Sheorey, 1999; Griffiths \& Parr, 2001; Kato, 2005). Oxford and Ehrman (1995) studied the strategy use of 520 participants and concluded that the most frequent strategies were compensation strategies. They also found that females used compensation strategies more than males.

In a different study, Martinez (1995) compared language learning strategy use of 50 secondary school students and 30 university students. Results indicated that although no considerable difference was found between university and school students, university students used more strategies than high school students. Spanish university students used cognitive and pronunciation strategies the most and memory and compensation strategies the least.

In addition, Sheorey (1999) found that meta-cognitive strategies were used most frequently. 1261 Indian college students were involved in the study wherein it was reported that the cultural background and the educational patterns influenced some of the strategies which Indian students used. Moreover, concerning gender and proficiency, it was found that female learners used strategies more frequently than male learners, and learners who had a high proficiency in English used functional practice strategies more frequently than learners who had a lower proficiency in English.

Kato (2005) indicated that Meta-cognitive-Affective strategies were used most frequently and Entrance- ExamMeasured strategy, which was a characteristic of students of Chinese, was used least frequently. Also, like the above studies, he found gender differences in strategy use. In addition, students who used Meta-cognitive-Affective, Social and Cognitive strategies were successful in learning, but students who used Memory-Compensation and EntranceExam-Measured strategies were not. Contrary to Sheorey (1999) and Su (2005), Kato (2005) showed that students' use of strategies was not related to their proficiency.

Moreover, there are those, like Hong-Nam and Leavell (2006), who believe that nationality affects the use of language learning strategies. They conducted a study with 55 ESL students from various countries to consider the relationships among the use of language learning strategies, proficiency, gender and nationality. Results indicated that intermediate students used more learning strategies than other proficiency level students. In addition, it was found that students used meta-cognitive strategies the most. Also, they used affective and memory strategies the least. Concerning the relationship between nationality and the use of language learning strategies, it was reported that Chinese (China and Taiwan) students used social strategies the most and memory and affective strategies the least. Students from Japan, Korea and Other (Brazil, Germany, Indonesia, Malaysia, Thailand, Togo) used meta-cognitive strategies the most; students of Japanese and Other used affective strategies, and Korean students used memory strategies the least.

Investigating the relationship between language learning strategies and years of studying English with English proficiency of students, Magno (2010) conducted a study with 302 Korean students. Findings indicated that compensation strategies significantly enhanced students' English proficiency. Also, it was reported that the more students spend time learning formal English, the more their English proficiency increases. So, students can choose the most appropriate strategies to apply.

Similarly, Radwan (2011) investigated the effect of gender and English proficiency on the use of language learning strategies. Meta-cognitive strategies and memory strategies were found to be used the most and the least, respectively. Furthermore, students with high proficiency level used cognitive, meta-cognitive and affective strategies more than students with low proficiency level. Also, supporting Sheorey (1999), it was suggested that EFL cultural environment may affect the type of strategies students use.

\subsection{Attitude}

One of the factors affecting the choice of language learning strategies is attitude. Ajzen (2005) defines attitude as "a disposition to respond favorably or unfavorably to an object, person, institution, or event" (p. 3). He also believes that attitude is a construct which is not reachable to direct observation, so measurable responses are required. A study by Charney, Newman and Palmquist (1995) showed that students' attitude as well as belief affect their thought, what they do while reading and writing, and their success.

Little attention has been paid to the relationship between attitude and language learning strategies. Here is a brief review of the few available studies in this regard.

Believing that quantitative analysis of learners' test scores is not sufficient, Chen (2007) conducted a qualitative analysis of students' learning process in a listening comprehension strategic program. 64 junior college students in Taiwan 
participated in the study. He maintains that since strategy training motivates learners to learn, changes in learners' behaviour and attitudes are its outcome. Based on the results, these changes were categorized into learners' behaviour, internal learning processes, learners' approach as well as their attitudes to foreign language learning.

Moreover, Macaro and Erler (2008) conducted an intervention study with young beginner learners of French to investigate their reading comprehension. Based on the results, strategy instruction not only enhanced students' comprehension of simple and complicated texts and developed their attitudes concerning reading, but also caused changes in students' strategy use.

In a different study, Gokce (2008) conducted a study with 170 students of high school sections of vocational high schools and 155 students of Anatolian high schools to investigate their motivational intensity as well as their attitudes, the difference between Anatolian high schools and vocational high schools, differences in gender toward motivational intensity, learning English as well as Anglo-Saxon culture. Results indicated that students of high school sections of vocational high schools had more positive attitudes. Also, female learners were reported to have more positive attitudes than male learners. In addition, although quantitative analysis showed that vocational high school students had a high level of motivation, attitudes concerning Anglo-Saxon culture and learning English, qualitative analysis only showed approximately positive attitudes of students concerning learning English. Results also showed negative attitudes of nearly half of the students regarding learning Anglo-Saxon culture and no motivational intensity of half of the students.

Additionally, Ghazali, Setia, Muthusamy and Jusoff (2009) investigated attitudes toward text selection, students' preferences in reading as well as the effect of teaching strategies used by teachers. Results showed that although students were less eager toward strategies, they had positive attitude about text selection. It was suggested that teachers have an important role not only in teaching content to students but also in shaping their attitudes. They also can choose interesting strategies to develop the attitudes of students.

Furthermore, $\mathrm{Wu}$ (2010) conducted a study consisting of 754 Taiwanese students majoring in Engineering, Business and Language to investigate the effect of two variables including gender and major on their strategy use. Results indicated that students used compensation and cognitive strategies the most and social and affective strategies the least. Also, the level of students' use of strategies was moderate. Concerning preferred strategies, their preference was direct strategies. In addition, there was a considerable relationship among major, gender and the use of strategies. The students majoring in language used strategies more than engineering and business students. Wu (2010) also found that female students used social strategies more than males. Furthermore, a high correlation was found between the attitude of learners toward learning and the number of strategies which students used.

To conclude, as the above mentioned studies show, attitude and language learning strategies are important factors in language learning and teaching. However, there are few studies which have paid attention to the direct relationships between them. Therefore, the present study aims to investigate the effect of attitude on the choice of compensation and meta-cognitive learning strategies of EFL learners.

\section{Method}

\subsection{Participants}

In the present study, a sample of 158 Iranian EFL students studying Teaching English and English Translation (both males and females) at Qazvin and Takestan State and Islamic Azad Universities was selected. After the administration of The Michigan Test of English Language Proficiency and taking the results into account, the number of participants was reduced to 108 . The students' proficiency level corresponded roughly to the intermediate level and their age ranged from 19 to 29.

\subsection{Instruments}

To answer the research questions, the following instruments were made use of: First, to homogenize the participants, a general proficiency test (The Michigan English Language Proficiency Test) was administered at the outset of the study. Second, a modified version of Oxford's SILL (Strategy Inventory for Language Learning) with 15 strategy items on a 5point Likert scale from 'Never' to 'Always' was given to the participants. A copy of the questionnaire is given in Appendix A. The questionnaire was divided into two categories:

1- Compensation strategies which had six items (Part A).

2- Meta-cognitive strategies which included nine items (Part B).

Finally, a language learning attitude questionnaire on a 5-point Likert scale from 'strongly disagree' to 'strongly agree', which included 27 items was given to them (See appendix B).

\subsection{Procedures}

The following procedures were followed in order to achieve the purpose of the present study. First, to remove anxiety, all the participants were informed about the purpose of the study. Also, to encourage them, it was explained that 1 point would be awarded to everyone who filled out the questionnaires truthfully. Then, a general proficiency test was administered to make sure that there were no significant differences among the participants in terms of their proficiency level. The participants had 45 minutes for the test. Those participants whose score were within one standard deviation below and above the mean were selected for the study and the remaining participants were excluded from all subsequent analyses. Next, in another session, the strategy and attitude questionnaires were given to all the participants. The participants had 50 minutes to complete these two questionnaires. To analyze the obtained data and to answer the research questions, two separate one-way ANOVA procedures were used. 


\section{Results and Discussion}

\subsection{Investigation of the First Research Question}

The first research question attempted to see whether attitude influences EFL learners' choice of compensation strategies. To this end, participants were divided into three equal groups of high, medium, and low level of attitude based their scores on the attitude questionnaire. ANOVA was used to see the effect of attitude level on the choice of compensation strategies. Table 1 contains the descriptive and test statistics. Based on Table 1, the high attitude group has the highest mean $($ mean $=20.72)$, followed by the medium attitude group (mean $=18.66)$, and the low attitude group (mean $=$ 16.33). Also, $F$-value is statistically significant $(F=19.407, p<.01)$. So, the differences among three attitude groups in the choice of compensation strategies are significant.

Table 1. Descriptive and Test Statistics for the ANOVA on Attitude and Compensation Strategies

\begin{tabular}{|c|c|c|c|c|c|c|}
\hline & \multirow[t]{2}{*}{ Attitude } & \multirow[t]{2}{*}{$\mathrm{N}$} & \multirow[t]{2}{*}{ Mean } & \multirow[t]{2}{*}{$\begin{array}{c}\text { Std. } \\
\text { Deviation }\end{array}$} & \multicolumn{2}{|c|}{$\begin{array}{l}\text { 95\% Confidence Interval for } \\
\text { Mean }\end{array}$} \\
\hline & & & & & Lower Bound & $\begin{array}{l}\text { Upper } \\
\text { Bound }\end{array}$ \\
\hline & High & 36 & 20.72 & 3.13 & 19.66 & 21.78 \\
\hline \multirow{3}{*}{$\begin{array}{l}\text { Compensation } \\
\text { Strategies }\end{array}$} & Mid & 36 & 18.66 & 2.72 & 17.74 & 19.58 \\
\hline & Low & 36 & 16.33 & 3.09 & 15.28 & 17.38 \\
\hline & \multicolumn{3}{|c|}{$\mathrm{F}=19.407$} & Sig $=$. & \multicolumn{2}{|c|}{$\omega^{2}=.25$} \\
\hline
\end{tabular}

As Table 1 shows, 25 percent of the total variance in the dependent variable, compensation strategies, is accounted for by the independent variable, attitude. This means that the remaining 75 percent of the variance in the dependent variable is left unaccounted for.

To locate the differences among the groups, the post hoc Sheffe test procedure was used, yielding the following results:

Table 2. Post Hoc Multiple Comparisons of Attitude Groups in the Choice of Compensation Strategies

\begin{tabular}{cccccc}
\hline $\begin{array}{c}\text { (I) Motivation } \\
\text { Group }\end{array}$ & $\begin{array}{c}\text { (J) Motivation } \\
\text { Group }\end{array}$ & $\begin{array}{c}\text { Mean } \\
\text { Difference (I-J) }\end{array}$ & Sig. & \multicolumn{2}{c}{$95 \%$ Confidence Interval } \\
\cline { 5 - 6 } & Mid & $2.05^{*}$ & .017 & Lower Bound & Upper Bound \\
\hline High & Low & $4.38^{*}$ & .000 & 2.63 & 3.80 \\
High & Low & $2.33^{*}$ & .005 & .58 & 6.13 \\
Mid & $*$
\end{tabular}

Figure 1 shows the differences among the three attitude groups more clearly.

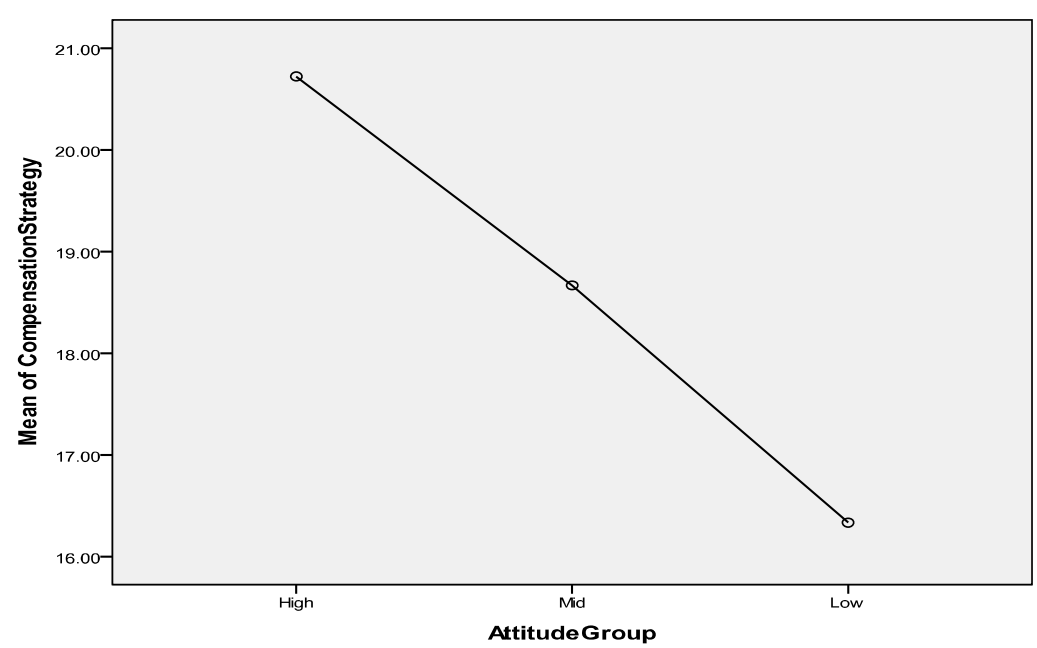

Figure 1. The Differences among the three Attitude Groups and the Choice of Compensation Strategies

\subsection{Investigation of the second Research Question}

The second research question aimed to see whether attitude influences EFL learners' choice of meta-cognitive strategies. To this end, participants were divided into three equal groups of high, medium, and low level of attitude based on their scores on the attitude questionnaire and another ANOVA procedure was run. Table 3 summarizes the results of descriptive and test statistics. As Table 3 shows, the high attitude group has the highest mean $($ mean $=34.72)$, 
followed by the low attitude group (mean $=34.33$ ), and the medium attitude group (mean $=33.22$ ). In addition, the $\mathrm{F}$ value is insignificant $(\mathrm{F}=.772, \mathrm{p}>.05)$ implying that the differences among the three attitude groups in the choice of meta-cognitive strategies are not statistically significant.

Table 3. Descriptive and Test Statistics for the ANOVA on Attitude and Meta-cognitive Strategies

\begin{tabular}{|c|c|c|c|c|c|c|}
\hline & \multirow[t]{2}{*}{ Attitude } & \multirow[t]{2}{*}{$\mathrm{N}$} & \multirow[t]{2}{*}{ Mean } & \multirow[t]{2}{*}{$\begin{array}{c}\text { Std. } \\
\text { Deviation }\end{array}$} & \multicolumn{2}{|c|}{$\begin{array}{l}\text { 95\% Confidence Interval for } \\
\text { Mean }\end{array}$} \\
\hline & & & & & Lower Bound & Upper Bound \\
\hline \multirow{4}{*}{$\begin{array}{c}\text { Meta- } \\
\text { cognitive } \\
\text { Strategies }\end{array}$} & High & 36 & 34.72 & 4.82 & 33.08 & 36.35 \\
\hline & Mid & 36 & 33.22 & 5.78 & 31.26 & 35.17 \\
\hline & Low & 36 & 34.33 & 5.29 & 32.54 & 36.12 \\
\hline & & \multicolumn{3}{|c|}{$F=.772$} & Sig $=.465$ & \\
\hline
\end{tabular}

Figure 2 shows the results more conspicuously.

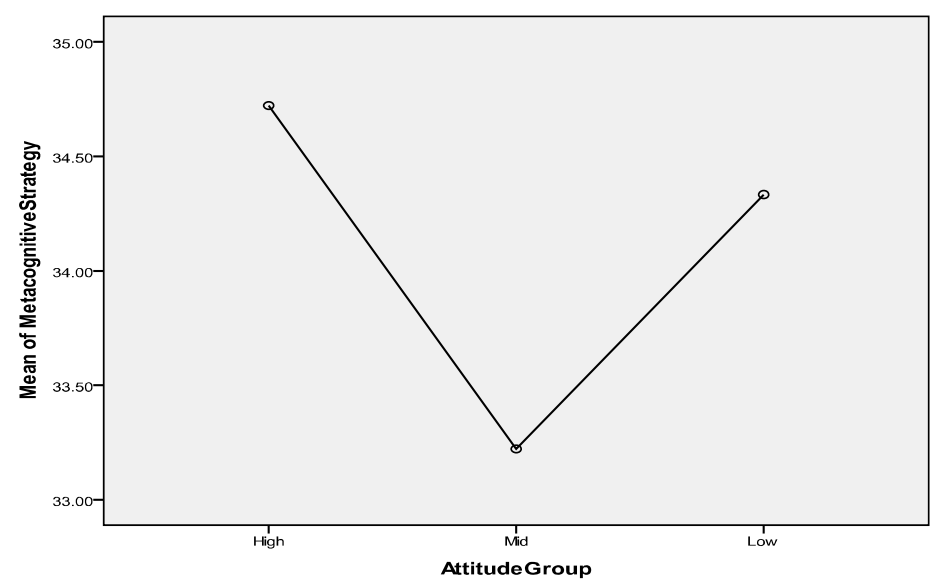

Figure 2. The Differences among the three Attitude Groups and the Choice of Meta-cognitive Strategies

\subsection{Discussion}

One of the findings of the present study was that attitude significantly influenced the choice of compensation strategies. This result lends support to those of Ames and Archer (1988), who found that students who emphasized mastery goals in the classroom, used more strategies and had a more positive attitude toward the class. Also, the findings of the present study supports Wu's (2010) findings that there is a high correlation between attitude of students toward learning and the number of strategies they use. Although types of attitude were not the focus of the present study, this study is in accordance with the findings of Sadighi and Zarafshan (2006), who found that students with positive attitudes used strategies more commonly than students with negative attitudes. At the same time, the findings of the present study are in contrast to those of $\mathrm{Su}$ (2005), who found that intermediate students used more learning strategies than other proficiency level students. In addition, although this study did not focus on any skill, the findings of the present study support those of Gupta and Woldemariam (2011), who found that students with high levels of attitude toward learning more frequently used writing strategies than students with lower levels of attitude.

A number of factors account for these findings. One of the reasons can refer to the Iranian socio-cultural educational setting in which students are used to following the teachers' instructions and where classes are predominantly teachercentered.

Another reason may be the participants' level of proficiency. The participants were all at intermediate proficiency level. Therefore, they may not have been much aware of the use of meta-cognitive strategies. This may explain why no significant differences were found among them. This claim is corroborated by studies such as Goh and Foong (1997), $\mathrm{Su}$ (2005), Wu (2008), Yang (2007), which accentuate the role of proficiency in using language learning strategies and indicate that more proficient students use some or all strategies more than less proficient students and that language proficiency affects students' use as well as selection of language learning strategies.

The other possible reason for such findings may be attributable to gender differences. In the present study, gender differences were not taken into account, whereas studies such as Arjomand and Sharififar (2011), Goh and Foong (1997), Green and Oxford (1995), Kato (2005), Radwan (2011) and Sheorey (1999) emphasize the prominent role of gender differences in the use, the choice and preference of language learning strategies.

Also, self-confidence and level of opportunities to use the target language in real environment can be addressed as the other possible factors which might have caused such findings. Iranian students have no or little opportunities to speak with native speakers of English. This may negatively affect their self-confidence to speak. This, in turn, may influence their ability to make use of various strategies. After all, practice makes perfect. 


\section{Conclusion}

The present study attempted to investigate the effect of attitude on the choice of compensation and meta-cognitive strategies of Iranian EFL learners. The results revealed that the level of attitude influence students' choice of compensation strategies, but have no significant effect on the choice of meta-cognitive strategies.

The findings of the present study may have implications for teachers as well as learners. As the effect of attitude on language learning is undeniable, the present study can help teachers and learners develop a better understanding of attitude in an educational context. In addition, teachers can find new and better ways of teaching to introduce strategies students does not know and increase students' attitude and the use of strategies.

\section{References}

Ajzen, I. (2005). Attitudes, Personality and Behavior. New York: Open University Press.

Ames, C. and Archer, J. (1988). Achievement goals in the classroom: students' learning strategies and motivation processes. Journal of Educational Psychology, 80(3), 260-267.

Arjomand, M. \& Sharififar, M. (2011). The most and least frequently used vocabulary learning strategies among Iranian EFL freshman students and its relationship to the gender. Iranian EFL Journal, 7(1), 91-100.

Chamot, A. U. (2004). Issues in language learning strategy research and teaching. Electronic Journal of Foreign Language Teaching, 1(1), 14-26.

Charney, D., Newman, John., H. \& Palmquist, M. (1995). "I'm just no good at writing": Epistemological style and attitudes toward writing. Written Communication, 12(3), 298- 329.

Chen, Y. (2007). Learning to learn: The impact of strategy training. ELT Journal, 61(1), 20-29.

Cottterall, S. (2000). Promoting learner autonomy through the curriculum: principles for designing language courses. ELT Journal, 54(2), 109-117.

Ehrman, M. E., leaver, B. L. \& Oxford, R. L. (2003). A brief overview of individual differences in second language learning. System, 31, 313-330.

Ghazali, S. N., Setia, R., Muthusamy, C. \& Jusoff, K. (2009). ESL students' attitudes towards texts and teaching methods used in literature classes. English Language Teaching, 2(4), 51-56.

Goh, C. M. C. \& Foong, K. P. (1997). Chinese ESL students' learning strategies: A look at frequency, proficiency, and Gender. Hong Kong Journal of Applied Linguistics, 2(1),39- 53.

Gokce, S. (2008). Attitudes and motivational intensity of foreign language learners at vocational high schools: A comparative study. Unpublished master's thesis. Middle East Technical University, Ankara.

Green, J. M. \& Oxford, R. (1995). A closer look at learning strategies, L2 proficiency, and gender. TESOL QUARTERLY, 29(2), 261-297.

Griffiths, C. \& Parr, J. M. (2001). Language-Learning strategies: theory and perception. ELT Journal, 55(3), 247-254.

Guilloteaux, M. J. \& Dornyei, Z. (2008). Motivating language learners: A classroom-oriented investigation of the effects of Motivational strategies on student motivation. TESOL Quarterly, 42(1), 55-77.

Gupta, D. \& Woldemariam, G. S. (2011). The influence of motivation and attitude on writing strategy use of undergraduate EFL students: Quantitative and qualitative perspectives. Asian EFL Journal, 13(2), 34-89.

Hong-Nam, K. and Leavell, A. G. (2006). Language learning strategy use of ESL students in an intensive English learning context. System, 34, 399-415.

Kato, S. (2005). How language learning strategies affect English proficiency in Japanese university students. Journal of the Faculty of Human Studies Bunkyo Gakuin University, 7(1), 239-262.

Macaro, E. \& Erler, L. (2008). Raising the achievement of young-beginner readers of French through strategy instruction. Applied Linguistics, 29(1), 90-119.

Magno, C. (2010). Korean students' language learning strategies and years of studying English as predictors proficiency in English. TESOL Journal, 2, 39-61.

Martinez, I. M. P. (1995). A study of the learning strategies used by secondary school and university students of English in Spain. Revista Alicantina de Estudios Ingleses, 8, 177-193.

Ortega, L. (2003). Syntactic complexity measures and their relationship to L2 proficiency: A research synthesis of college-level L2 writing. Applied linguistics, 24(4), 492-518.

Oxford, R., L. (1992). Who Are Our Students?: A Synthesis of Foreign and Second Language Research on Individual Differences with Implications for Instructional Practice. TESL CANADA Journal, 9(2), 30-49.

Oxford,R. \& Crookall, D. (1989). Research on language learning strategies: Methods, findings, and instructional issues. The Modern Language Journal, 73(4), 404-419.

Oxford, R, L. \& Ehrman, M. E. (1995). Adult's language learning strategies in an intensive Foreign language program in the United States. System, 23(3), 359-386. 
Radwan, A. A. (2011). Effects of L2 proficiency and gender on choice of language learning strategies by university students majoring in English. Asian EFL Journal,13(1), 114-162.

Sadighi, F. \& Zarafshan, M. (2006). Effects of attitude and motivation on the use of language learning strategies by Iranian EFL university students. Journal of Social Sciences and Humanities of Shiraz University, 23(1), 71-80.

Sheorey, R. (1999). An examination of language learning strategy use in the setting of an indigenized variety of English. System, 27, 173-190.

$\mathrm{Su}$, M. H. M. (2005). A study of EFL technological and vocational college students' language learning strategies and their self-perceived English proficiency. Electronic Journal of Foreign Language Teaching, 2(1), 44-56.

Vandergrift, L. (2005). Relationships among motivations, orientations, meta-cognitive awareness and proficiency in L2 listening. Applied Linguistics, 26(1), 70-89.

Wu, C. N. (2010). English learning strategy use among technological college students in Taiwan. Unpublished master's thesis. Pingtung University, Taiwan.

Wu, Y. L. (2008). Language learning strategies used by students at different proficiency level. Asian EFL Journal,10(4), 75-95.

Yang, M. N. (2007). Language learning strategies for junior college students in Taiwan: Investigating Ethnicity and proficiency. Asian EFL Journal, 9(2), 35-57.

\section{Appendix A: Language Learning Strategies Questionnaires}

Please answer to the following questions according to your true cases from 1 (Never or almost never true of me) to 5 (always or almost always true of me).

\section{Part A}

$$
\text { (1. Never 2. Rarely 3. Sometimes 4. Often 5. Always) }
$$

1. To understand unfamiliar English words, I make guesses.

2. When I can't think of a word during a conversation in English, I use gestures.

3. I make up new words if I do not know the right ones in English.

4. I read English without looking up every new word.

5. I try to guess what the other person will say next in English.

6. If I can't think of an English word, I use a word or phrase that means the same thing.

\section{Part B}

7. I try to find as many ways as I can to use my English.

8. I notice my English mistakes and use that information to help me do better.

9. I pay attention when someone is speaking English.

10. I try to find out how to be a better learner of English.

11. I plan my schedule so I will have enough time to study English.

12. I look for people I can talk to in English.

13. I look for opportunities to read as much as possible in English.

14. I have clear goals for improving my English skills.

15. I think about my progress in learning English.

\section{Appendix B: Attitude Questionnaire}

Fill out the following questionnaire, circling the one which best describes whether you agree or disagree with each statement. This is for yourself not for anyone else, so answer as honestly as you can.

$S D=$ Strongly Disagree $D=$ Disagree $\quad N=$ Neither agree nor disagree $A=$ Agree $S A=S t r o n g l y$ Agree

1. I think I'm a pretty good language learner.

2. Learning a language may be important to my goals, but I don't expect it to be much fun.

3. My language learning aptitude is probably pretty high.

4. I don't have any idea about how to go about learning a language.

SD $\quad \mathrm{D} \quad \mathrm{N} \quad \mathrm{A} \quad \mathrm{SA}$

SD $\quad \mathrm{D} \quad \mathrm{N} \quad \mathrm{A} \quad \mathrm{SA}$

SD $\quad \mathrm{D} \quad \mathrm{N} \quad \mathrm{A} \quad \mathrm{SA}$

SD D N A SA

5. I think that I could learn pretty much any language I really put my mind to, given the right circumstances.

6. I worry a lot about making mistakes.

7. I'm afraid people will laugh at me if I don't say things right.

8. I end up trembling and practically in a cold sweat when I have to talk in front of people.

9. I find it hard to make conversation even with people who speak my own language.

10. I feel a resistance from within when I try to speak in a foreign language, even if I've practiced.
$\mathrm{SD} \quad \mathrm{D} \quad \mathrm{N} \quad \mathrm{A} \quad \mathrm{SA}$

SD $\quad \mathrm{D} \quad \mathrm{N} \quad \mathrm{A} \quad \mathrm{SA}$

SD $\quad \mathrm{D} \quad \mathrm{N} \quad \mathrm{A} \quad \mathrm{SA}$

SD $\quad \mathrm{D} \quad \mathrm{N} \quad \mathrm{A} \quad \mathrm{SA}$
SD $\quad \mathrm{D} \quad \mathrm{N} \quad \mathrm{A} \quad \mathrm{SA}$ 
11. It is a mark of respect to people to learn their language if you're living in their country.

SD D N A

12. I like getting to know people from other countries, in general.

SD D N A SA

13. Speaking the language of the community where I'll be living will let me help people more than I could otherwise.

14. I don't like the idea of relying on speaking English (or my mother tongue) in another country.

SD $\mathrm{D} \quad \mathrm{N}$ A $\mathrm{SA}$

15. I think the people of the country where I'll be living would like for me to learn their language.

16. I won't really be able to get to know people well if I don't speak their language.

SD $D \quad N \quad A \quad S A$

SD $\mathrm{D} \quad \mathrm{N} \quad \mathrm{A} \quad \mathrm{SA}$

17. There is a right and a wrong way to do almost everything, and I think it's my duty to figure out which is which and do it right.

18. It annoys me when people don't give me a clear-cut answer, but just beat around the bush.

SD D N A

SD $\quad \mathrm{D} \quad \mathrm{N} \quad \mathrm{A} \quad \mathrm{SA}$

19. You should say "yes" if you mean yes and "no" if you mean no. Not to do so is dishonest.

SD D N A SA

20. You have to understand people's culture and value system before you can be sure whether some things are right or wrong.

21. I like to mimic other accents, and people say I do it well.

SD $\quad \mathrm{D} \quad \mathrm{N} \quad \mathrm{A} \quad \mathrm{SA}$

22. I can do impersonations of famous people.

SD $\quad \mathrm{D} \quad \mathrm{N} \quad \mathrm{A} \quad \mathrm{SA}$

23. I find it easy to "put myself in other people's shoes" and imagine how they feel.

SD D N A SA

SD $\quad \mathrm{D} \quad \mathrm{N} \quad \mathrm{A} \quad \mathrm{SA}$

24. In school, if I didn't know an answer for sure, I'd sometimes answer out loud in class anyway.

25. I often think out loud, trying out my ideas on other people.

$\mathrm{SD} \quad \mathrm{D} \quad \mathrm{N}$ A $\mathrm{SA}$

26. I want to have everything worked out in my own head before I answer.

SD D N A SA

27. I'd call myself a risk-taker.

SD D N A SA

SD D N A SA 